\title{
Lung herniation in the implantable cardioverter defibrillator pocket
}

\author{
Mashrafi Ahmed, Tahmina Begum
}

Texas Tech University, Amarillo, Texas, USA

\section{Correspondence to}

Dr Mashrafi Ahmed,

mashrafi.ahmed@ttuhsc.edu

Accepted 14 June 2015
CrossMark

To cite: Ahmed M, Begum T. BMJ Case Rep Published online: [please include Day Month Year] doi:10.1136/bcr-2015210703

\section{DESCRIPTION}

A 47-year-old Caucasian man with the medical history of hypertension, hypercholesterolaemia and non-ischaemic cardiomyopathy with ejection fraction $(\mathrm{EF})$ of $25-30 \%$ presented with pain in the left upper chest wall. Nearly 2 months earlier, he had undergone implantable cardioverter defibrillator (ICD) placement surgery for low EF. The initial attempt to place the biventricular lead was unsuccessful. Subsequently, he had epicardial lead placement performed by the cardiothoracic surgeon with repositioning of the ICD generator above the previous pocket. One week prior, he noticed a small bulging over the area of recent surgery, particularly during coughing. It got worse and, the day prior to admission, he started to develop severe pain over the area. The bulging was reproducible with cough or deep breathing, which caused severe pain. On physical examination, there was a bulging of the left upper anterior chest wall with coughing (video 1). A CT of the chest revealed herniation of the upper lobe of the left lung into the chest wall between the second and third rib in the previous ICD pocket (figures 1 and 2, white arrow). The patient underwent surgical repair of the anterior chest wall with Dulex mesh placement.

Herniation of the lung is a rare presentation of protrusion of a part of the lung through the chest wall. Protrusion of the lung occurs through a weak area of the thoracic cavity due to increased intrathoracic pressure by coughing, emesis, straining or lifting heavy weights. ${ }^{12}$ The weak area in the chest wall is related to congenital deformity or trauma, either surgical or accidental. ${ }^{2}{ }^{3} \mathrm{~A}$ spontaneous lung herniation is more common in men with chronic obstructive pulmonary disease, mostly due to chronic coughing and hyperinflation, in association with long-term steroid use. The anterior thoracic wall, between the eighth and ninth ribs, is the most commonly

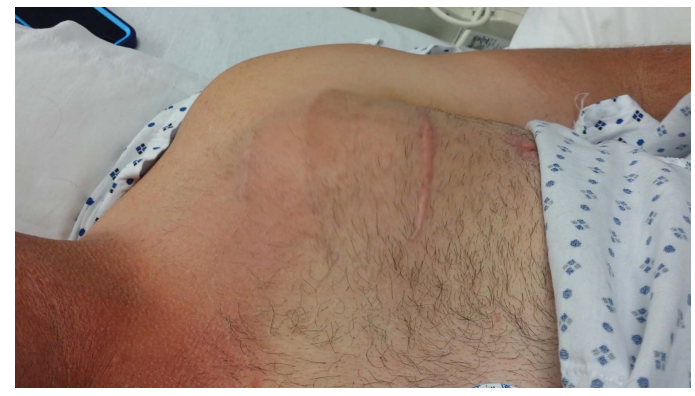

Video 1 Chest wall bulging due to lung herniation with forceful coughing. affected site due to diminished muscular support at this region. ${ }^{3}$ Lung hernia may be asymptomatic or may produce respirophasic bulging with or without pain. Incarceration, strangulation, haemoptysis or recurrent infections are possible, but rare, complications. In patients with symptoms or complications, a surgical approach with mesh placement or contraction of the intercostal space with percostal stitches may be considered. ${ }^{1}$

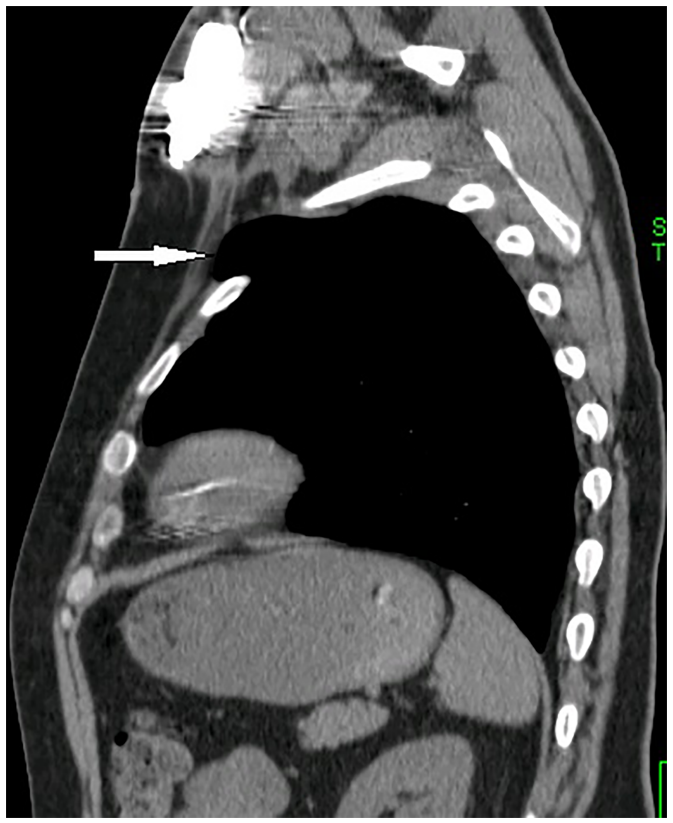

Figure $1 \mathrm{CT}$ of the chest (sagittal view) showing herniation of the lung through the intercostal space to the implantable cardioverter defibrillator pocket (white arrow).

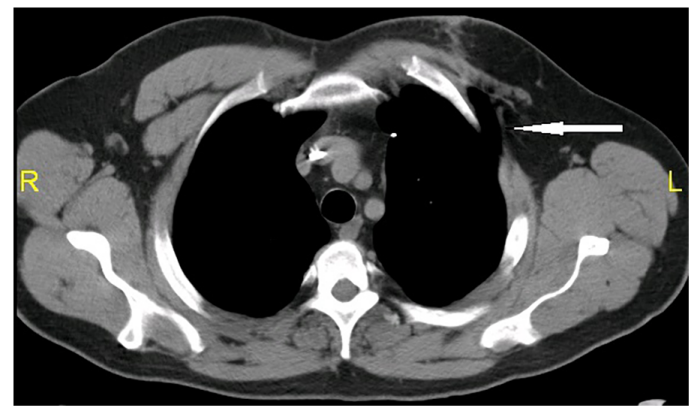

Figure 2 CT of the chest (axial view) showing herniation of the lung through the intercostal space to the implantable cardioverter defibrillator pocket (white arrow). 


\section{Learning points}

Lung herniation is a rare cause of chest wall pain and bulging.

- It may occur due to congenital chest wall defect or traumatic and postsurgical chest wall weakness.

- The bulging is reproducible with forceful expiration, coughing, emesis, straining or Valsalva manoeuvre.

- In symptomatic patients, surgical correction with mesh placement may be considered, though recurrence is not uncommon.
Competing interests None declared.

\section{Patient consent Obtained.}

Provenance and peer review Not commissioned; externally peer reviewed.

\section{REFERENCES}

1 Psathakis K, Mermigkis C, Tsintiris K. Transient lung herniation through a thoracic cage defect: a case report. Cases J 2009;2:7524.

2 Tack D, Wattiez A, Schtickzelle JC, et al. Spontaneous lung herniation after a single cough. Eur Radiol 2000;10:500-2.

3 Sulaiman A, Cottin V, Pereira de Souza Neto E, et al. Cough induced intercostal lung herniation requiring surgery: report of a case. Surg Today 2006;36:978-80.

Copyright 2015 BMJ Publishing Group. All rights reserved. For permission to reuse any of this content visit http://group.bmj.com/group/rights-licensing/permissions.

BMJ Case Report Fellows may re-use this article for personal use and teaching without any further permission.

Become a Fellow of BMJ Case Reports today and you can:

- Submit as many cases as you like

- Enjoy fast sympathetic peer review and rapid publication of accepted articles

- Access all the published articles

- Re-use any of the published material for personal use and teaching without further permission

For information on Institutional Fellowships contact consortiasales@bmjgroup.com

Visit casereports.bmj.com for more articles like this and to become a Fellow 